\title{
Selected Indicators of Population ageing in the World: Trends, Impacts and Consequences
}

\author{
Slavomír Bucher ${ }^{\mathrm{A}}$ \\ Received: June 16, 2014 | Revised: July 10, 2014 | Accepted: August 4, 2014
}

\begin{abstract}
The macro regional differences expressed through some indicators of population ageing may reflect social and economic disparities in the World. The current research considers the relationship between selected ageing parameters like ageing index, potential support ratio, parental support, the old age dependency coefficient, longevity index and centenarian index in the World macro regions. The main objective of the study is to focus and describe the forecast of population ageing - the demographic phenomenon in the World characterised by a reduction in fertility, a decrease in mortality rate, and higher life expectancy among World population from 2015 through 2050. The gradually declining proportion of youth and productive population in the next decades will be accompanied in most countries across the World by a constant growth in the share of post-productive population. Based on data from the Unite Nations (UN), their section "Population Division, Population Estimates and Projection Section" and the topic "World population Prospects: The 2012 Revision", this study, endeavour determinate and understand actions in health and social sphere, which would lead to alleviation the negative consequences of ageing.

Unfortunately, the ageing forecasts for macro regions are not optimistic. Therefore, it will be beneficial to identify outcomes related to specific needs of non-working oldest-old cohorts like the availability of social and healthcare support for elderly people.
\end{abstract}

Key words: Ageing population, indicators of population ageing, macro regions, population structure, social and health consequences, ageing forecast

\section{Introduction}

The current trends in ageing or the rejuvenation of the population might be the result of the interaction between different consequences and circumstances by several demographic and socioeconomic factors. Global ageing is diagnosed by following general indicators: prolonging the duration of life, a reduction in the proportion of the young population as the impact outflow fertility rate below the level of replacement. These conditions have contradicted intensity in different regions and societies.

A number of studies indicate significant importance about decrease mortality in older age groups over the World and growth of the elderly population, which might lead to the ageing population globally
(Kurek, 2004; Binstock, George, 2011; Miskolczi, et al., 2011; Bucher, 2012a, 2012b).

The level of ageing in current World macro regions is determined by the reduction of fertility and the long-term improvements in mortality and also predominantly in Europe and Northern America female autonomy, individualism, increase in personal freedom, selfishness and narcissism in developed societies. In our survey measuring with methods which evaluated absolute and relative ageing processes in society. The absolute ageing is linked with the attributes like grows of life expectancy and median age, increase of post-productive population (seniors) in the total population also labelled as the ageing from the top. The relative ageing is affiliated with the features

\footnotetext{
A Department of Geography and Applied Geoinformatics, Faculty of Humanities and Natural Sciences, University of Prešov, Ul. 17 novembra 1, 08001 Prešov, Slovakia

* Corresponding author: Slavomir Bucher, e-mail: slavobucher@yahoo.com
} 
of declining the natality also called as the ageing from the bottom.

Predominant articles treat with the relationship between population ageing, longevity, and health in Europe, Northern America or developed Asian countries. Only of few survey spotlights on mortality patterns in later life, active life expectancy and social class, health and longevity (Bongaarts, 2007; Robine, et al., 1999; Lynch, 2003; Magnolfi, et al., 2007; Długosz, 2011; Kurek, 2003; Botev, 2012).

Matlovič, et al. $(2005,2008)$ pointed out on differentiated development in particular regions based on selected socio-economical indicators.

\section{Methods and data}

The evaluation of statistical data about ageing might be expressed by primary indicators of ageing for instance selected age categories, persons in post-productive and productive age (65 and over, 65-74, 75$84,85+, 0-14)$. For analysis and comparison have been adopted medium variant of age structure according to the UN projection database in the periods 2015-2050 and data were compared for following continents and macro regions: Africa, Asia, Europe - Eastern, Northern, Southern, Western, Latin America and the Caribbean, Northern America, Oceania and the World. Hence, 11 territorial units were taken into the account.

The ageing index, potential support ratio, parental support, the old age dependency coefficient, longevity index and centenarian index in material need for evaluation were exploited as a relative indicators associated with the ageing. All indicators were calculated and projected for each continent/macro region in two separate years of 2015 and 2050.

The ageing index was expressed as the proportion of the number of persons in 65 and over age group per 100 persons in 0-14 years old. Potential support ratio was obtained as the number of people in the working ages of 15-64 per every person 65 or older. Parental support is defined as the ratio of the number of persons in the age group of 85 years and older and the number of persons in the age group of 50-64. An old age dependency coefficient represents the number of people in 65 and over per 100 people in 15-64 years old. Longevity index is the ratio between the number of people in the age group 90-99 and the total population over 65 years old. The last one is the centenarian index, which symbolized prevalence of centenarians $(100+)$ within the ultra-nonagenarians (90-99).

\section{Results}

The proportion of people in the age category of 65 years and more (Figure 1) will range from $3.5 \%$ (Africa) to
$17.3 \%$ (Europe) in 2015. In 2050, the proportion moved to the range starting at the level of $5.9 \%$ (Africa) to 26.9 $\%$ (Europe). The average values for World population will increase between 2015 and 2050 by 7.4 percentage points from $8.2 \%$ to $15.6 \%$. In 2015, the share of persons aged 65 and over in the total population will be in $\mathrm{Eu}-$ rope higher that the persons younger than 15 . Over the next 35 years, there will be only three continents (Africa, Asia and Oceania), where the proportion of children aged o-14 will exceed the share of persons older than 65 years. A forecast based on the, World Population Prospects: The 2012 Revision" shows that the population above 65 years old is more frequent in the Europe and Northern America as compared to Africa or Asia. The evaluation of different macro-regions in Europe had revealed that the oldest population could be located in Southern Europe, where the share of persons above 65 , are the highest. At the same period of evaluation among the European macro-regions, the region of Northern Europe is the youngest one, where the popu-
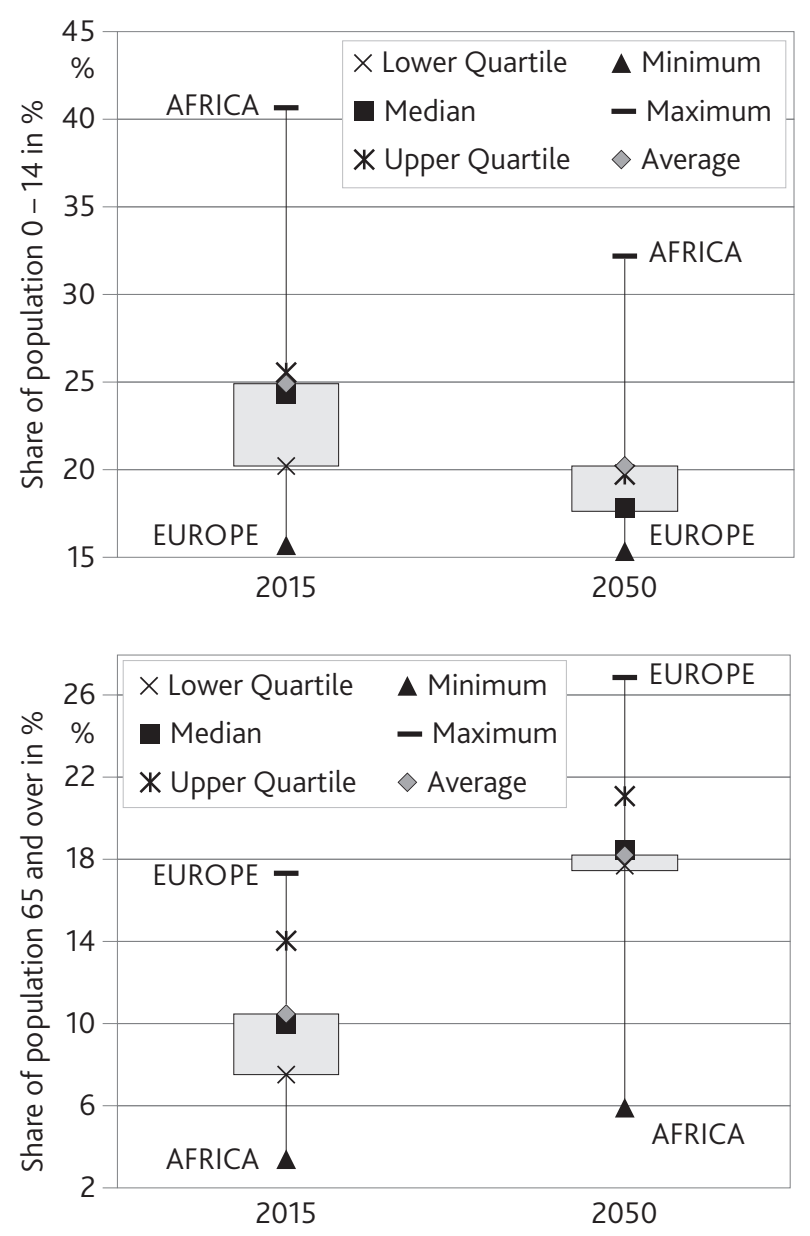

Figure 1. The comparison of pre-productive and postproductive age categories in the World's macro-regions. The gray square illustrates the values that are the most represented in the group

Source: Compiled by the author based on UN "World population Prospects: The 2012 Revision - medium fertility variant" 
lation below 15 years counted for $17.6 \%$ in 2015 respectively $16.9 \%$ in 2050.

A lot of papers compare statistical data about ageing in the context of the proportion of young-old group aged (65-74), old-old aged (75-84) and oldest-old aged
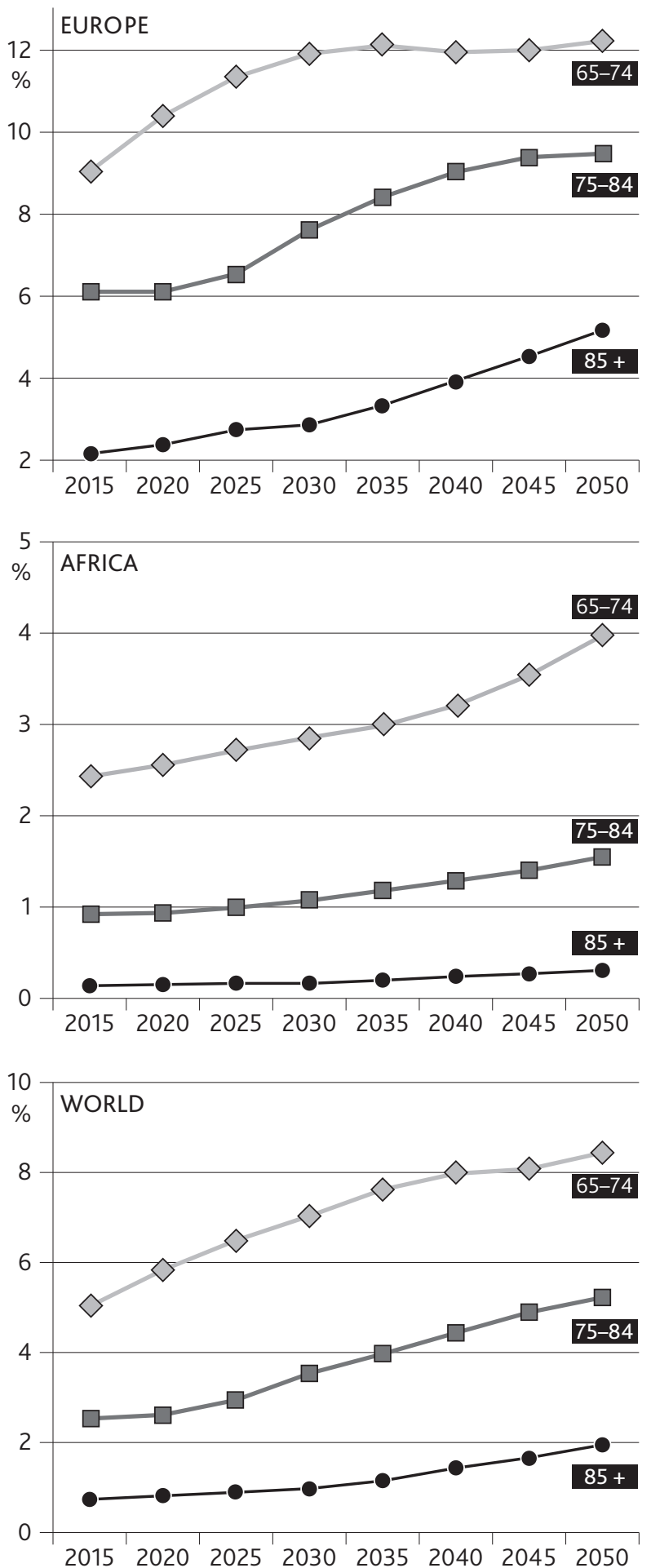

Figure 2. The development of post-productive age groups in the Europe (the oldest continent), Africa (the youngest continent) and World Source: Compiled by the author based on UN "World population Prospects: The 2012 Revision - medium fertility variant"
$(85+)$ from the total population. In the World will be projected to have $1.9 \%$ people aged 85 years and over in 2050, whereas in 2015, this proportion it will be only 0.7 $\%$. On a global level, the 85 -and-over population will be projected to increase in absolute values from 54 million in 2015 to 185 million in 2050. In Europe, the proportion of people aged $85+$ from the total population will be $2.2 \%$ in 2015 and is projected to be $5.2 \%$ in the year 2050 (projection within the medium fertility). In absolute values, this will be represented by 36.8 million of the total population of 709 million in the Europe (2050). The post-productive population (people aged 65 or older) might be the rapidly growing portion of the population in Europe and Northern America (Figure 2).

The following figure (Figure 3) describes the distribution of the population by five-year age groups and sex. The next three age pyramids for 2015 a 2050 present the structure of the population of the World, Africa (the youngest continent) and Europe (the oldest continent) for the projected period. The outlined characteristics of all three pyramids in 2050 are their decreasing base, which is caused by the declining number of births - an aftermath of a very intense decline in fertility marked predominantly in Europe. The population pyramid of Europe in 2015 will be narrower at the bottom and will be shaped more as a rhomboid due to the baby-boom cohorts of the 1960s. The survey of projection of the European population summarized in the form of age pyramids unequivocally indicates that the demographically old European population in the 2015 will become demographically the oldest in the World by the end of the projection horizon in 2050. The 2015 age pyramid is still progressive in Africa, in indicating a young age structure and low level of demographic old age. The shapes of the age pyramid for the projection in 2050 for Africa will still resemble a triangle although their bases will start to shrink due to the decreasing number of births. While the age pyramid in the World for 2015 might be counted among the type close to a progressive population, the age pyramid for the year 2050 will be representing a stagnant population. The development of the total population in the World will be in the close future affected by many demographic processes like natural shifts in population age structure, migrations, constant mortality and low fertility.

The ageing index of the inhabitants in the World and continents according to the projection will be characterized by a rapidly growing trend, compared to the year 2015 the ageing index in the World's population will increase from $31.7 \%$ to $73.2 \%$ in the year 2050, for the youngest continent from $8.6 \%$ to $18.2 \%$ and for the oldest continent from $110.1 \%$ to $174.9 \%$. The European macro-regions and Europe as a whole will be between 2015 and 2050 among those with the 

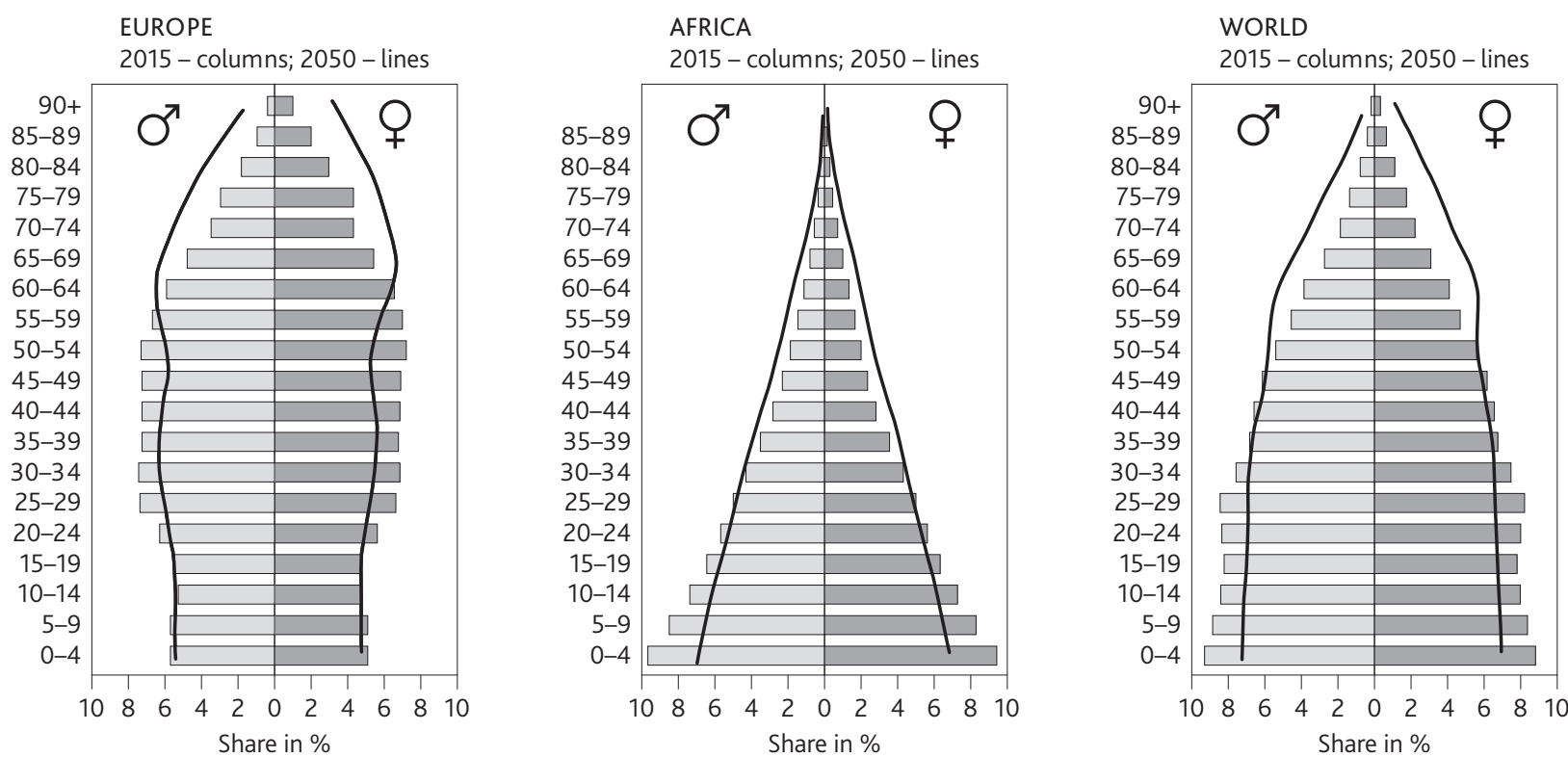

Figure 3. The age pyramids in the Europe (the oldest continent), Africa (the youngest continent) and World Source: Compiled by the author based on UN "World population Prospects: The 2012 Revision - medium fertility variant"

highest ageing index. In contrast, continents like Africa, Asia will be among those with the lowest ageing index. Ageing index indirectly represents economic aspects of ageing, which could be related to the allowances and pensions. In 2050, the fast ageing in the World will have serious social and economic impact, among others, strong pressure on health services and social system. Due to societal transformation of the age structure, the shrinking proportion of youth people and fast growing of elderly people will be affected the labor market, employment, the pension system and sustainability of social and health care.

The next synthetic indicator represents an old dependency ratio, which measure the relative balance between those who might be potential, dependents" (65 and over) and those who may be marked as a possible supporters (15-64). The old age dependency ratio values in the forecast for 2050 will be contrasting for many different continents. The old age dependency ratio is extremely high in all European sub-regions, ranging from $38.5 \%$ in Eastern Europe to $61.1 \%$ in Southern Europe (2050) demonstrating, in the lastmentioned case, more than six dependents for every 10 adults under 65 . The lowest values will be recorded in Africa, $9.5 \%$ and Asia $27 \%$. For the whole World, this index will have a gradual increase. Its value will reach $12.5 \%$ in 2015 . The index will increase to $24.7 \%$ in 2050. This means that economic active population who affords economic and social benefits for the elderly people will be gradually shrinking over next 35 years.

A significant measure of the population aging process is the potential support ratio (as a variation of the elderly dependency ratio). This indicator is formulated as the ratio of the number of persons in the working age group of
15-64 and the number of persons in the age group 65 and older (theoretically retired). Increasing life expectancy is the cause of the decreasing of potential support ratio. According to the projection between 2015 and 2050 this index in the World will be gradually falling. The index in the World's macro-regions will decline to $797.5 \%$ in 2015 and a further drop to $404.6 \%$ in 2050. This reflects that the productive part of the population (15-64) will ensure harder necessary economic and social needs of the postproductive part of the population. The development of values of the potential support ratio will be between 2015 and 2050 different from region to region. However, in 2015 projected index values will range from $1600.5 \%$ (Africa) to $386.3 \%$ (Europe) and in 2050 from $1057.7 \%$ (Africa) to $214.7 \%$ (Europe).

Parental support ratio presents an important measure of population ageing. It expresses a relation between people in age category of 85 years and older and the number of people in the age category 50-64 year olds. Population with the higher index is characterized as older; there are a higher proportion of people who are, theoretically the children of the people in age category of 85 years and older. The Parental support ratio in the macro-regions according to the projection 2050 will be between $2.9 \%$ (Africa) and $28.3 \%$ (Europe). In 2015, the parental support index in the World will reach $5.2 \%$. It means that there will be 5 elderly people per 100 people aged 50-64. The age structure forecasts will show that, in 2050, mentioned index will be doubled. The projections for 2050 are showing the significantly different values for different regions in the World. The highest values will be observed in European regions like Southern Europe (39.7 \%), Western Europe (38.2 \%) while Africa (2.9\%) and Asia (9.5\%) will record the low- 
est index values. We come to the conclusion that the parental support ratio in the period 2015-2050 will be growing the most intensively in Europe (17.6 percentage points) and in Northern America (17.2 percentage points). It will be the result of the increase the life expectancy globally thanks to better care and physical, mental wellness in most developed countries.

In total, at 1 July 2050, there will be 3.4 million centenarians in the World. More than one third of centenarians ( 1.5 million) will be living in Asia, followed by 650 thousand centenarians in Latin America and Caribbean. At the end of the projection 2050 the highest value of longevity index (\%) will be found in Northern America (8.9 \%), followed by Oceania (8.3 \%) and Europe ( $7.6 \%$ ). On the opposite side, the lowest value will be found in Africa (1.4\%), followed by Asia (3.3\%).

The centenary index (calculated in percentage) figures will behave differently in 2050. Especially, they will be the highest in the Latin America and Caribbean $(7.3 \%)$, in the Oceania (6.1 \%) and Europe (5.2 $\%)$ compared to the lowest ones in the Africa (1.8\%), Northern America and Asia (4.9\%).

It is relevant to observe that in the macro regions demonstrating the lowest longevity (\%) and centenary index (\%) values the dominant segment of population lives in the countries of Africa with the unstable eco-
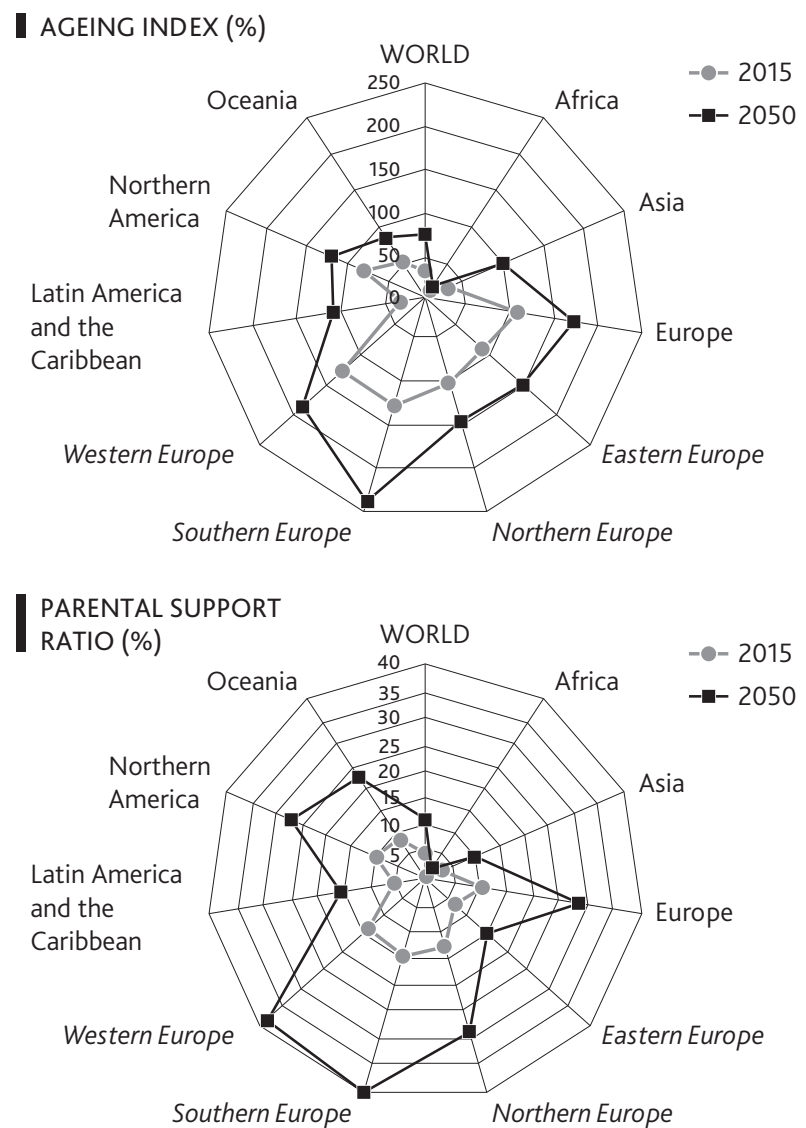

nomic (high level of unemployment between economic active population), political (with corrupted and collapsed of the governments in power), social (insufficient social security and support systems to the ageing society) and health system (lack of preventive care, treatment and long term nursing service).

The countries with developed health-care system and high level of sanitary, technological and economic condition have a higher percentage in all elderly sub-population groups (the young old, the old and the oldest-old). We assume that longevity index is affected by the social, healthcare and technological progress.

A correlation of various data for World continents uncovers that the oldest population may be found in Europe, where both the percentage of persons above 65 and a share of the centenarians reach the maximum values. The continents like Africa and Asia are the youngest one, where the population above 65 years will achieve in 2015 respectively 2050 only to $3.5 \%$ (Africa), $7.5 \%$ (Asia) or $5.9 \%$ (Africa), $17.4 \%$ (Asia). In total, in 2015, there will be half million centenarians in the World. About a quarter of them (125 thousand persons) will be living in the Europe, 19 thousand in the Eastern ones, 24 thousand in Northern Europe, 36 thousand in Southern Europe and 46 thousand in Western Europe (Figure 4).

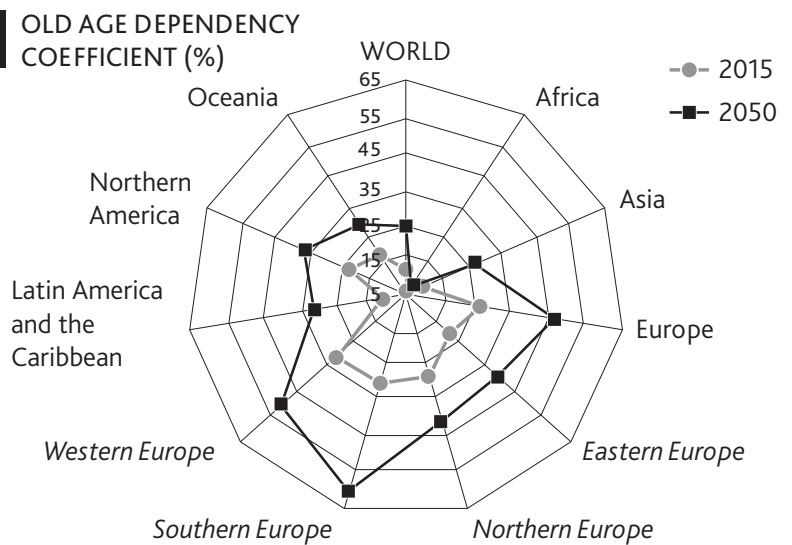

I LONGETIVITY INDEX (\%)

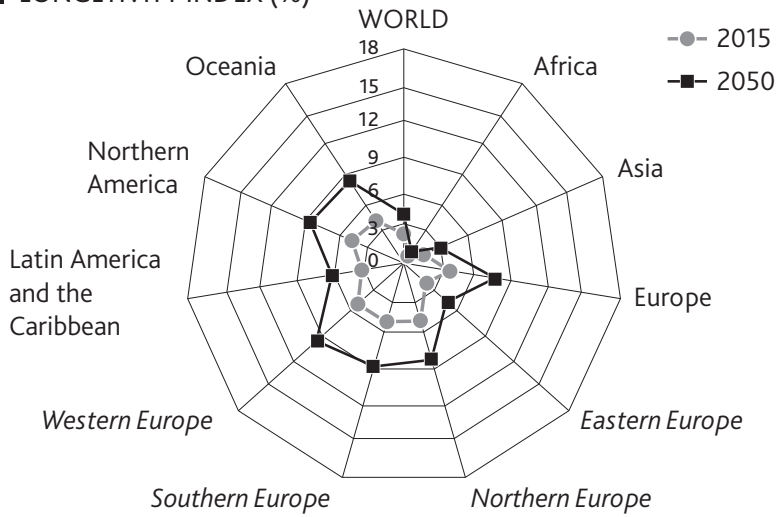

Figure 4. The projection of selected indicators of ageing the World's population Source: Compiled by the author based on UN "World population Prospects: The 2012 Revision - medium fertility variant" 
Table 1 A. Primary parameters of population ageing in the World 2015

\begin{tabular}{|l|r|r|r|r|r|r|}
\hline \multirow{2}{*}{2015} & \multicolumn{5}{|c|}{ Parameters } \\
\cline { 2 - 7 } & $0-14(\%)$ & $65+(\%)$ & $65-74(\%)$ & $75-84(\%)$ & $85(\%)$ & Male 100+ (\%) \\
\hline Africa & 40.6 & 3.5 & 2.4 & 0.9 & 0.1 & 24.5 \\
\hline Asia & 24.4 & 7.5 & 4.7 & 2.2 & 0.5 & 24.9 \\
\hline Europe & 15.7 & 17.3 & 9.1 & 6.1 & 2.2 & 17.6 \\
\hline Eastern Europe & 15.8 & 14.4 & 7.7 & 5.2 & 1.4 & 15.7 \\
\hline Northern Europe & 17.6 & 18.0 & 10.0 & 5.7 & 2.3 & 17.0 \\
\hline Southern Europe & 14.9 & 19.4 & 9.7 & 6.9 & 2.7 & 22.3 \\
\hline Western Europe & 15.4 & 19.8 & 10.0 & 7.0 & 2.8 & 15.1 \\
\hline Latin America and the Carribean & 26.1 & 7.6 & 4.6 & 2.3 & 0.8 & 32.5 \\
\hline Northern America & 19.1 & 14.8 & 8.5 & 4.4 & 1.9 & 17.2 \\
\hline Oceania & 23.7 & 11.9 & 6.9 & 3.5 & 1.5 & 18.0 \\
\hline WORLD & 26.0 & 8.2 & 5.0 & 2.5 & 0.7 & 23.5 \\
\hline
\end{tabular}

Table 1 B. Synthetic parameters of population ageing in the World 2015

\begin{tabular}{|c|c|c|c|c|c|c|}
\hline \multirow{2}{*}{2015} & \multicolumn{6}{|c|}{ Parameters } \\
\hline & $\mathrm{Al}(\%)$ & PSR (\%) & PS (\%) & OADC (\%) & $\mathrm{LI}(\%)$ & $\mathrm{Cl}(\%)$ \\
\hline Africa & 8.6 & 1600.5 & 1.9 & 6.2 & 0.8 & 1.2 \\
\hline Asia & 30.7 & 909.6 & 3.8 & 11.0 & 2.0 & 2.8 \\
\hline Europe & 110.1 & 386.3 & 10.6 & 25.9 & 3.9 & 2.5 \\
\hline Eastern Europe & 91.2 & 485.5 & 6.8 & 20.6 & 2.3 & 1.9 \\
\hline Northern Europe & 102.1 & 357.7 & 12.5 & 28.0 & 4.7 & 2.8 \\
\hline Southern Europe & 130.3 & 339.7 & 13.7 & 29.4 & 4.6 & 2.6 \\
\hline Western Europe & 128.4 & 327.4 & 13.3 & 30.5 & 4.8 & 2.5 \\
\hline Latin America and the Carribean & 29.3 & 868.1 & 5.7 & 11.5 & 3.4 & 6.1 \\
\hline Northern America & 77.5 & 446.6 & 9.8 & 22.4 & 4.7 & 3.3 \\
\hline Oceania & 50.0 & 542.6 & 9.3 & 18.4 & 4.4 & 2.7 \\
\hline WORLD & 31.7 & 797.5 & 5.2 & 12.5 & 2.7 & 3.0 \\
\hline
\end{tabular}

Note: Al (\%) - Ageing index, PSR (\%) - Potential support ratio, PS (\%) - Parental support, OADC (\%) - Old age dependency coefficient, LI (\%) - Longevity index, $\mathrm{Cl}(\%)$ - Centenarian index

Source: Compiled by the author based on UN "World population Prospects: The 2012 Revision - medium fertility variant"

Table 2 A. Primary parameters of population ageing in the World 2050

\begin{tabular}{|l|r|r|r|r|r|r|}
\hline \multirow{2}{*}{2050} & \multicolumn{6}{|c|}{ Parameters } \\
\cline { 2 - 7 } & $0-14(\%)$ & $65+(\%)$ & $65-74(\%)$ & $75-84(\%)$ & $85(\%)$ & Male 100+ (\%) \\
\hline Africa & 32.2 & 5.9 & 4.0 & 1.6 & 0.3 & 17.1 \\
\hline Asia & 17.9 & 17.4 & 9.6 & 6.0 & 1.8 & 23.5 \\
\hline Europe & 15.4 & 26.9 & 12.2 & 9.5 & 5.2 & 19.3 \\
\hline Eastern Europe & 16.0 & 23.3 & 13.1 & 7.3 & 2.9 & 18.1 \\
\hline Northern Europe & 16.9 & 24.3 & 10.5 & 8.8 & 5.0 & 27.7 \\
\hline Southern Europe & 13.7 & 32.7 & 13.6 & 12.2 & 6.9 & 18.5 \\
\hline Western Europe & 15.0 & 28.4 & 11.0 & 10,5 & 6.8 & 16,6 \\
\hline Latin America and the Carribean & 17.6 & 19.3 & 9.9 & 6.4 & 3.0 & 27.1 \\
\hline Northern America & 18.0 & 21.8 & 9.7 & 7.4 & 4.7 & 22.2 \\
\hline Oceania & 20.4 & 17.9 & 8.3 & 6.0 & 3.6 & 23.3 \\
\hline WORLD & 21.3 & 15.6 & 8.4 & 5.2 & 1.9 & 23.1 \\
\hline
\end{tabular}


Table 2 B. Synthetic parameters of population ageing in the World 2050

\begin{tabular}{|c|c|c|c|c|c|c|}
\hline \multirow{2}{*}{2050} & \multicolumn{6}{|c|}{ Parameters } \\
\hline & $\mathrm{Al}(\%)$ & PSR (\%) & PS (\%) & OADC (\%) & LI (\%) & $\mathrm{Cl}(\%)$ \\
\hline Africa & 18.2 & 1057.7 & 2.9 & 9.5 & 1.4 & 1.8 \\
\hline Asia & 97.4 & 370.5 & 9.5 & 27.0 & 3.3 & 4.9 \\
\hline Europe & 174.9 & 214.7 & 28.3 & 46.6 & 7.6 & 5.1 \\
\hline Eastern Europe & 146,2 & 260.0 & 14.9 & 38.5 & 4.6 & 2.7 \\
\hline Northern Europe & 144,0 & 242.0 & 28.4 & 41.3 & 8.1 & 5.6 \\
\hline Southern Europe & 239,0 & 163.6 & 39.7 & 61.1 & 8.5 & 5.9 \\
\hline Western Europe & 188,6 & 199.5 & 38.2 & 50.1 & 9.7 & 5.6 \\
\hline Latin America and the Carribean & 109,5 & 328.1 & 16.0 & 30.5 & 5.9 & 7.3 \\
\hline Northern America & 121,1 & 276.6 & 27.0 & 36.2 & 8.9 & 4.9 \\
\hline Oceania & 87,7 & 345.1 & 22.3 & 29.0 & 8.3 & 6.1 \\
\hline WORLD & 73,2 & 404.6 & 11,5 & 24.7 & 4.4 & 5.2 \\
\hline
\end{tabular}

Note: Symbols are of the same meaning, as in Table $1 B$.

Source: Compiled by the author based on UN "World population Prospects: The 2012 Revision - medium fertility variant"

\section{Conclusion}

The study demonstrates that the ageing process among the continents in the World's population can be predicted by selected primary and synthetic indicators. The primary and synthetics indexes of an ageing population, according to the projection (medium fertility) do not seem to be very optimistic for continents in our survey. It might be noted that dynamics of population ageing process can be forecasted the most beneficial scenario for Africa. Ageing is a phenomenon continuing all over the World. In some of the analysed macro regions ageing process develops so fast and will be predicted to increase further. In 2050, it will be projected that $5.2 \%$ of the total population in Europe will be aged 85 and over. We expect that Europe in 2050 will be the oldest continent in the World. The swift transformation of the age structure in World the "decampment" of youth people and the rapid increase of elderly cohorts give rise to essential health and social issues, among others; difficult tension on health and social services like the encouragement of healthy habits and health status monitoring, treatment and long term medical services to meet the ageing society's demands.

Most of the published studies dealing with population ageing; refer to the significant relationship between socioeconomic and ageing indicators (Hoff, 2008; Walberg, et al., 1998; Pool, 2007; Mason, 2007; Preston et al., 2000). There are also papers, which come to similar outcomes as in our study. These analyses evaluate the impact that ageing is having in the World; examines trends, impacts and responses within the next few decades (Barr, et al., 2006; Menon, et al., 2009)

The changes between mortality, health and ageing have a strong impact on the influence of the socio- economic situation on the perception of old age. For the population live in macro regions with lower social status and financial poorer conditions are characterized with higher fertility rates and progressive young structure of the age pyramid. Comparing with last decades the life expectancy in all regions has increased. Therefore, considering that the demographic ageing process is perceived by majority working people adversely, and the position of older people in society remains questionable, because the negative image of old people (helplessness, prevention, irritation, apathy, disease, etc.) and support with potential of solving its problems related to older persons by society is still limited.

\section{Acknowledgment}

The article is part of the grant research project VEGA No. 1/0325/12. Intra-urban structure dynamics in Slovakia in the first decade of the 21st century (2012 - 2014).

\section{References}

Barr, N., Diamod, P.A. 2006. „The Economics of Pensions". Oxford Review of Economic Policy, 22 (1): 3915.

Binstock, R.H., George, L.K. 2011. Handbook of Aging and the Social Sciences. $7^{\text {th }}$ edition: Elsevier.

Bongaarts, J. 2007. How long will we live? Population Development Review, 32 (4): 628-605.

Botev, N. 2012. Population ageing in Central and Eastern Europe and its demographic and social context. European Journal of Ageing, 9 (1): 79-66.

Bucher, S. 2012a. Population aging and changes in the age structure of Slovakia. Revija za geografijo: journal for geography, 7 (1): 24-7. 
Bucher, S. 2012b. Aspects of the phenomenon of demographic population aging in Czechia and Slovakia: time and regional dimensions. Human geographers: Journal of studies and research in human geography, 6 (1): 33-25.

Długosz, Z. 2011. Population ageing in Europe. The and International Geography Symposium GEOMED2010. Procedia Social Social and Behavioral Sciences, 19: 55-47.

Hoff, A. 2008. Population Ageing in Central and Eastern Europe as an Outcome of the Socio-economic Transition to Capitalism. Socialinis darbas, 7 (2): 25-14.

Kurek, S. 2003. The spatial distribution of population ageing in Poland in the years 1988-2001. Bulletin of Geography (Socio-Economic series), 2: 75-65.

Kurek, S. 2004. The population ageing process against vital statistical changes in polish towns. Bulletin of Geography (Socio-economic series), 3: 95-83.

Lynch, S. 2003. Cohort and life-course patterns in the relationship between education and health: A hierarchical approach. Demography, 40: 331-309.

Magnolfi, S.U., Petruzzi, E., Pinzani, P., Malentacchi, F., Pazzagli, M., Antonini, F.M. 2007. Longevity index (LI \%) and centenarity index (CI \%): New indicators to evaluate the cahracteristics of aging process in the Italian population. Archives of Gerontology and Geriatrics, 44: 276-271.

Matlovič, R., Matlovičová, K. 2005. Vývoj regionálnych disparít na Slovensku a problémy regionálneho rozvoja Prešovského kraja. Acta Facultatis Studiorum Humanitatis et Naturae Universitatis Prešoviensis, Prírodné vedy, Folia Geographica, 8: 66-88.
Matlovič, R., Klamár, R., Matlovičová, K. 2008. Development of regional disparities in slovakia at the beginning of 21st century based on the selected indicators. Czech Regional Studies, 2: 2-12.

Mason, A. 2007. Demographic transition and demographic dividends in developed and developing countries. Proceedings of the United Nations Expert Group Meeting on Social and Economic Implications of Changing Population Age Structures Mexico City, 31 August - 2 September 2005, New York: United Nations, 101-81.

Menon, J., Melendez, A.C. 2009. Ageing in Asia. Trends, Impacts and Responses. ASEAN Economic Bulletin, 26 (3): 305-293.

Miskolczi, M., Langhamrová, J., Langhamrová, J. 2011. Ageing indicators in selected countries of the European Union. Research journal of economics, business and ICT, 3: 55-52.

Pool, I. 2007. Demographic dividends: determinants of development or merely windows of opportunity? Ageing Horizons, 7: 35-28.

Preston, S.H., Heuveline, P., Guillot, M. 2000. Demography: Measuring and Modelling Population Processes. Oxford: Blackwell Publishers.

Robine, J.M., Romieu, I., Cambois, E. 1999. Health expectancy indicators. Bulletin of World Health Organization, 77: 185-181.

United Nations - Population Division, Population Estimates and Projections 2013. World Population Prospects: The 2012 Revision, New Yourk UNFPA. Walberg, P., McKee, M., Shkolnikov, V., Chenet, L., Leon, D.A. 1998. Economic change, crime, and mortality crisis in Russia: regional analysis. British Medical Journal, 317 (7154): 318-312. 